\title{
Nutritional therapy optimization in COVID-19 critically ill patients
}

\section{Optimización de la terapia nutricional en el paciente crítico con COVID-19}

\author{
Francisco G. Yanowsky-Escatell ${ }^{1}$ and Iván A. Osuna-Padilla ${ }^{2 *}$ \\ ${ }^{1}$ Hospital Civil de Guadalajara Dr. Juan I. Menchaca, Department of Internal Medicine, Nutrition Department, Jalisco, Mexico; ${ }^{2}$ Instituto Nacional \\ de Enfermedades Respiratorias, Infectious Diseases Research Center, Mexico City, Mexico
}

Currently, COVID-19, caused by the new severe acute respiratory syndrome coronavirus 2 (SARSCoV-2), represents a threat to global public health. Infected patients are at risk of developing acute respiratory distress syndrome. Reports indicate that $5 \%$ to $10 \%$ of the infected population will require admission to an intensive care unit (ICU) and invasive mechanical ventilation. ${ }^{1}$ Due to inability of patients in this condition to be orally fed, nutritional therapy should be considered a component of comprehensive treatment of this emerging disease.

An important proportion of the SARS-CoV-2-infected population has overweight or obesity; a body mass index $>28 \mathrm{~kg} / \mathrm{m}^{2}$ has been reported to be a risk factor for disease severity (odds ratio $=5.872,95 \%$ $\mathrm{Cl}=1.595-21.621, \mathrm{p}=0.008) .{ }^{2}$ However, the presence of overweight or obesity does not justify the prescription of fasting in critically ill patients, since in other clinical conditions, up to $60 \%$ of patients with obesity admitted to the ICU have been documented to have malnutrition, ${ }^{3}$ which is why nutritional therapy should be optimized in order to prevent deterioration or improve nutritional status. Regardless of the body mass index, malnutrition in the critically ill patient is a serious problem, given that it is associated with an increased risk of infections, incidence of pressure ulcers, increased hospital costs and higher mortality. ${ }^{4,5}$

Critical disease evolves in two phases: acute phase (catabolism) and post-acute phase (anabolism). In turn, the acute phase is divided in two periods: an early period (one or two days), characterized by metabolic instability and a severe increase in catabolism; and late period (three to seven days), defined by significant muscle wasting and stabilization of metabolic alterations. In the post-acute phase, the patient can improve, rehabilitate or remain in a persistent catabolic/ inflammatory state and prolonged hospitalization. ${ }^{6}$

Critically ill patients are in a state of catabolic stress and inadequate ingestion, which predisposes them to malnutrition. ${ }^{7}$ Critically ill patients whose ICU stay is longer than 48 hours should be considered at risk of malnutrition, which is why they should be prescribed medical nutritional therapy, defined by the European Society for Clinical Nutrition and Metabolism (ESPEN) as the provision of nutrients by oral, enteral (enteral nutrition, EN) or parenteral route (parenteral nutrition, $\mathrm{PN}$ ). ${ }^{6}$

There are no specific data on nutritional interventions in patients with COVID-19 and their impact on clinical outcome. Table 1 mentions the recommendations of the COVID-19 patient nutritional management guidelines, recently issued by the British Dietetic Association ${ }^{8}$ and ESPEN, ${ }^{9}$ which include suggestions from ESPEN, ${ }^{6}$ the American Society of Parenteral and Enteral Nutrition ${ }^{10}$ and the German Society for Nutritional Medicine ${ }^{11}$ for the critically ill patient, and which can be modified according to the evolution of knowledge and the epidemic.

Medical nutritional therapy will depend on the clinical condition and degree of malnutrition of the patient. Starting EN within the first 48 hours of ICU stay is suggested, ${ }^{6}$ due to its benefits on gastric mucosa, synthesis of hormones and enzymes, and immune 
Table 1. Recommendations for medical nutritional therapy in critically ill patients with COVID-19

\begin{tabular}{|c|c|}
\hline Process & Recommendation \\
\hline Malnutrition risk & - Consider all critically ill patients with an ICU stay longer than 48 hours at risk of malnutrition. \\
\hline Nutritional assessment & $\begin{array}{l}\text { - Assess weight and height. If there are no stretcher-integrated scales, estimate them with predictive } \\
\text { equations. } \\
\text { - Assess hemodynamic stability (vasopressor dose, mean blood pressure, acid-base balance, serum } \\
\text { lactate). } \\
\text { - Quantify energy input coming from medications (use of citrate, dialysis solutions, propofol, dextrose } \\
\text { infusions). } \\
\text { - Assess metabolic control through parameters such as glucose and triglycerides. } \\
\text { - Identify patients at higher risk for developing refeeding syndrome (phosphorus, potassium and } \\
\text { magnesium concentrations). }\end{array}$ \\
\hline Medical nutritional therapy & $\begin{array}{l}\text { - Establish EN as the first feeding route (first } 48 \text { hours). } \\
\text { - Use a gastric tube as the first option or post-pyloric feeding if there is gastric intolerance despite } \\
\text { treatment with prokinetics or in the presence of high risk of aspiration. } \\
\text { - Select standard polymeric ( } 1-1.5 \mathrm{kcal} / \mathrm{mL} \text { ) or densely energetic enteral formulas ( } 1.5-2 \mathrm{kcal} / \mathrm{mL} \text { ) when } \\
\text { volume restriction is sought. There are no benefits with the use of specialized formulas for lung disease. } \\
\text { - Invasive mechanical ventilation in prone decubitus is no contraindication for EN infusion. } \\
\text { - PN should be implemented in case of contraindication for EN, at between three and seven days } \\
\text { of hospital stay. It can be early and progressive when there is contraindication for EN in severely } \\
\text { malnourished patients or if there is intolerance to EN. } \\
\text { - Start complementary PN in patients in whom } 100 \% \text { of requirements have not been reached after } \\
\text { seven days of EN. } \\
\text { - Use standardized (triple chamber) or individualized PN formulas. } \\
\text { - Prescribe } 20-25 \mathrm{kcal} / \mathrm{kg} \text { of ideal weight; provide } 70 \% \text { of requirements on first three days and } 80 \% \text { to } \\
100 \% \text { after day } 3 \text {. } \\
\text { - Provide } 1.3 \mathrm{~g} / \mathrm{kg} \text { of protein (amount that should be reached between days } 3 \text { and } 5 \text { ), with input being } \\
\text { increased by } 1.7-2.5 \mathrm{~g} / \mathrm{kg} / \text { day in patients with acute kidney injury on renal replacement treatment. }\end{array}$ \\
\hline $\begin{array}{l}\text { Medical nutritional therapy } \\
\text { monitoring }\end{array}$ & $\begin{array}{l}\text { - Check EN or PN infused volume. } \\
\text { - Monitor for the appearance of signs of gastrointestinal intolerance (diarrhea, abdominal distension, } \\
\text { vomiting, gastric residue }>500 \mathrm{~mL} \text { ) or intestinal ischemia, fluid balance and serum electrolytes. } \\
\text { - Direct physical examination to nutritional status in order to identify possible signs of nutrient deficits. } \\
\text { - Monitor hemodynamic stability and vasopressor doses. Delay medical nutritional therapy start or } \\
\text { progression in patients with instability, staggered doses or double vasopressor support. }\end{array}$ \\
\hline $\begin{array}{l}\text { Post-mechanical ventilation } \\
\text { period and dysphagia }\end{array}$ & $\begin{array}{l}\text { - Perform swallowing test prior to starting oral route, once invasive mechanical ventilation has been } \\
\text { removed. } \\
\text { - Prescribe consistency-modified diet in case of swallowing alteration. } \\
\text { - Continue EN in patients whose swallowing is not safe. } \\
\text { - Prescribe EN via post-pyloric tube if there is high risk of aspiration; if not feasible, use PN during the } \\
\text { dysphagia rehabilitation period. }\end{array}$ \\
\hline
\end{tabular}

$\mathrm{ICU}=$ intensive care unit, $\mathrm{EN}=$ enteral nutrition, $\mathrm{PN}=$ parenteral nutrition.

response regulation. ${ }^{12}$ Should there be any contraindication for EN, PN should be established at between three and seven days. The use of early and progressive PN should be considered in severely malnourished subjects, with contraindication for or intolerance to EN. ${ }^{6,9}$

Nutrimental intake should be gradually increased: within the first three days, providing $70 \%$ of energy requirements is suggested, and then increase until reaching 80 to $100 \%$. Protein intake should be $1.3 \mathrm{~g} /$ $\mathrm{kg} /$ day. If during the first week covering all patient energy and protein requirements is not possible with EN, PN initiation should be evaluated in an individualized manner. 6,9
Even when international guidelines suggest the incorporation of nutrition protocols in ICUs, several studies have reported that knowledge, training and time for prescribing medical nutritional therapy are insufficient in the medical and nursing team. ${ }^{13,14}$ Due to the above, the American Society of Parenteral and Enteral Nutrition suggests considering nutrition as a therapeutic process in the management of critically ill patients and incorporating a clinical nutritionist, ${ }^{15}$ which is the professional in charge of prescribing, implementing and monitoring this intervention, into the ICU. ${ }^{16}$

The COVID-19 pandemic continues to spread in Latin America, which increases the burden for public and private health systems. The care of patients with 
this disease is not only concentrated in ICUs, it also takes place in other hospitalization areas. Therefore, knowing the implications of medical nutritional therapy and current nutritional recommendations will optimize COVID-19 treatment and evolution in patients.

\section{References}

1. Poston JT, Patel BK, Davis AM. Management of critically ill adults with COVID-19. JAMA. 2020;323:1839-1841.

2. Jordan RE, Adab P, Cheng KK. COVID-19: risk factors for severe disease and death. BMJ. 2020;368:m1198. DOI: https://doi.org/10.1136/bmj.m1198

3. Robinson MK, Mogensen KM, Casey JD, McKane CK, Moromizato T Rawn JD, et al. The relationship among obesity, nutritional status, and mortality in the critically ill. Crit Care Med. 2015:43:87-100.

4. Barker LA, Gout BS, Crowe TC. Hospital malnutrition: prevalence, identification and impact on patients and the healthcare system. Int J Environ Res Public Health. 2011;8:514-527.

5. Ruiz AJ, Buitrago G, Rodríguez N, Gómez G, Sulo S, Gómez C, et al Clinical and economic outcomes associated with malnutrition in hospitalized patients. Clin Nutr. 2019;38:1310-1316.

6. Singer P, Blaser AR, Berger MM, Alhazzani W, Calder PH, Casaer MP, et al. ESPEN guideline on clinical nutrition in the intensive care unit. Clin Nutr. 2019;38:48-79.

7. Lee ZY, Heyland DK. Determination of nutrition risk and status in critically ill patients: what are our considerations? Nutr Clin Pract. 2019;34:96-111.
8. British Dietetic Association [Internet]. Bear D, Terblanch E. Birmingham. Critical Care Specialist Group Guidance on management of nutrition and dietetic services during the COVID-19 pandemic. 2020; Mar 23. Available at: https://www.bda.uk.com/resource/critical-care-dietetics-guidance-covid-19. html

9. Barazzoni R. ESPEN expert statements and practical guidance for nutritional management of individuals with SARS-CoV-2 infection. Clin Nutr. 2020;39:1631-1638.

10. McClave SA, Taylor BE, Martindale RG, Warren MM, Johnson DR, Braunsvhweig $\mathrm{C}$, et al. Guidelines for the provision and assessment of nutrition support therapy in the adult critically ill patient: Society of Critical Care Medicine (SCCM) and American Society for Parenteral and Enteral Nutrition (A.S.P.E.N.). J Parenter Enteral Nutr. 2016;40:159-211.

11. Elke G, Hartl WH, Kreymann KG et al. Clinical nutrition in critical care medicine - Guideline of the German Society for Nutritional Medicine (DGEM). Clin Nutr ESPEN. 2019;33:220-275.

12. Allen K, Hoffman L. Enteral nutrition in the mechanically ventilated patient. Nutr Clin Pract. 2019;34:540-557.

13. Mowe M, Bosaeus I, Rasmussen HH, Kondrup J, Unosson M, Rothenberg $\mathrm{E}$, et al. Insufficient nutritional knowledge among health care workers? Clin Nutr. 2008:27:196-202

14. Grammatikopoulou MG, Katsouda A, Lekka K, Tsantekidis K, Bouras E, Poulia KA, et al. Is continuing medical education sufficient? Assessing the clinical nutrition knowledge of medical doctors. Nutrition. 2019;57:69-73.

15. Tappenden KA, Quatrara B, Parkhurst ML, Malone AM, Fanjiang G, Ziegler TR. Critical role of nutrition in improving quality of care: an interdisciplinary call to action to address adult hospital malnutrition. J Parenter Enteral Nutr. 2013;37:482-497.

16. Terblanche $\mathrm{E}$. The role of dietitians in critical care. J Intensive Care S 2019;20:255-257. 